\title{
Interação genótipo x local x regime alimentar em bovinos nelore por meio de componentes principais de três modos
}

\author{
Genotype $x$ location $x$ feeding interactions in Nellore cattle calculated through three-mode principal \\ component analysis
}

\author{
Ingryd Loiola Franco ${ }^{\mathrm{I}}$ Carlos Henrique Mendes Malhado ${ }^{\mathrm{I} I \mathrm{I}^{*}}$ Paulo Luiz Souza Carneiro ${ }^{\mathrm{II}}$ \\ Raimundo Martins Filho ${ }^{\text {III }}$ Derval Gomes Pereira ${ }^{\text {II }}$ Carlos Tadeu dos Santos Dias ${ }^{\text {IV }}$
}

\section{RESUMO}

O principal objetivo deste estudo foi aplicar componentes principais com múltiplas matrizes de dados para verificar a interação tripla genótipo x local $x$ regime alimentar no valor genético do efeito direto do peso, aos 205 dias de idade. Foram utilizados touros com filhos em três regiões de produção do Nordeste Brasileiro (Maranhão, Mata e Agreste, e Recôncavo Baiano) e criados nos regimes alimentares a pasto ou com suplementação. Não se evidenciou interação genótipo x local para a característica estudada, entretanto, constatou-se interação do genótipo x regime alimentar. A utilização dos touros deve ser direcionada de acordo com o regime alimentar de seus filhos.

Palavras-chave: múltiplas matrizes, análise de agrupamento, efeito ambiental, modelos multiways.

\section{ABSTRACT}

The main objective of this study was to apply threemode principal component analysis to assess the triple interaction (genotype $x$ location $x$ feeding) on direct genetic value for weight at 205 days of age. We used 60 sires with offspring in three regions of northeastern Brazil (Maranhão, Mata and Agreste, and Recôncavo Baiano) and raised on a pasture regime or with supplementation. There was no interaction between genotype and location, but there was a correlation between genotype and direct effect of feeding. The use of sires should be dictated according to the system of rearing of their offspring.

Key words: cluster analysis, environmental effect, multiple arrays, multiways models.

\section{INTRODUÇÃO}

A diversidade de climas e manejo no Brasil resulta em diferentes sistemas de produção. Isso é acentuado no Nordeste, região que apresenta grande diversidade agroecológica expressa na existência de áreas úmidas, subúmidas, semi-áridas e áridas (ARRUDA \& SUGAI, 1994). No Brasil, alguns pesquisadores (ELER et al., 2000; SOUZA et al., 2003; TORAL et al., 2004; FRIDRICH et al., 2008; LOPES et al., 2008) fizeram estudos para avaliar a existência de interação genótipo $\mathrm{x}$ ambiente para características de crescimento em bovinos de corte, considerando o ambiente como a região ou local de criação. Entretanto, esses estudos não abordaram a interação do genótipo com o regime alimentar e a literatura não relata estudos envolvendo a interação tripla genótipo x local x regime alimentar com bovinos. Isso é particularmente importante para o Brasil, notadamente na Região Nordeste, onde os rebanhos de elite são mantidos em condições ambientais e alimentares muito diferentes daquelas às quais estão submetidos os rebanhos comerciais.

O estudo da interação tripla genótipo x local $\mathrm{x}$ regime alimentar é possível com a análise de componentes principais de três modos (three way analysis), que explica os resíduos da interação tripla

'Universidade Estadual do Sudoeste da Bahia (UESB), Campus Itapetinga, Itapetinga, BA, Brasil.

"UESB, 45200-000, Campus Jequié, Jequié, BA, Brasil. E-mail: carlosmalhado@gmail.com. Autor para correspondência.

${ }^{\mathrm{II}}$ Universidade Federal do Ceará (UFC), Campus do Cariri, Juazeiro do Norte, CE, Brasil.

${ }^{\text {IV }}$ Departamento de Ciências Exatas, Escola Superior de Agricultura Luiz de Queiroz (ESALQ), Universidade de São Paulo (USP), Piracicaba, SP, Brasil. 
associados a um modelo linear com três fontes de variação, e permite estudar padrões de desempenhos de genótipos por ambientes e fazer predições a respeito da performance média de genótipos a ambientes específicos por meio de representação gráfica, nos chamados biplots (representação gráfica simultânea dos genótipos, regiões e regimes alimentares). A aplicação dessa metodologia é inédita no melhoramento genético animal. Contudo, já foi recentemente utilizada na genética vegetal em estudo com feijão (ARAÚJO et al., 2010) e milho (ARAÚJO et al., 2011). Assim, o objetivo principal deste estudo foi avaliar a interação tripla do genótipo com dois regimes alimentares em três regiões de criação na região Nordeste em bovinos da raça Nelore, por meio de análise de componentes de três modos e comparar os resultados com técnicas tradicionais de avaliação de interação genótipo versus ambiente.

\section{MATERIAL E MÉTODOS}

Foram utilizados 12.450 pesos padronizados aos 205 (P205) dias de idade de bovinos da raça Nelore, nascidos entre 1976 e 2006, incluídos no controle de desenvolvimento ponderal da Associação Brasileira de Criadores de Zebu (ABCZ). As regiões de produção foram caracterizadas de acordo com ARRUDA \& SUGAI (1994). O estado do Maranhão (Região de Produção 22, R1) constitui uma nítida faixa de transição entre o clima equatorial úmido amazonense e o semiúmido nordestino. A Zona da Mata e Agreste (Região de produção 26, R2), embora com condições climáticas bem distintas, possui cerca de $90 \%$ do gado bovino existente nesta região, pertencentes às áreas do agreste. O Agreste é a área de transição entre a Zona da Mata e o Sertão, estende-se por uma vasta área dos estados brasileiros da Bahia, Sergipe, Alagoas, Pernambuco, Paraíba e Rio Grande do Norte. O Recôncavo Baiano (região de produção 28, R3) é uma região de clima quente e com alta densidade bovina.

Foram considerados dois regimes alimentares: exclusivamente a pasto (F1) e com suplementação, confinados ou não confinados (F2). Os touros analisados possuíam no mínimo 10 filhos em cada combinação região/regime alimentar. Utilizaramse os 60 touros com maior número de filhos para representação gráfica nos biplots.

Para obter as estimativas das variâncias e dos valores genéticos, empregou-se a metodologia da máxima verossimilhança restrita livre de derivada, por meio de modelos animais tri-característica, com uso do aplicativo MTDFREML (BOLDMAN et al., 1995). Os grupos de contemporâneos foram formados por animais do mesmo sexo, nascidos na mesma estação e ano de nascimento e pertencentes à mesma fazenda. Grupos de contemporâneos contendo menos de três animais foram excluídos da análise, totalizando 8670 animais. $\mathrm{O}$ modelo estatístico considerou o efeito fixo de grupos de contemporâneos (831), a idade da vaca ao parto como covariável (efeitos linear e quadrático), o efeito aleatório genético (direto e materno) e o efeito não correlacionado de ambiente permanente materno. A covariância entre os efeitos genéticos direto e materno foi considerada zero.

O modelo linear para a interação de três modos foi:

$\bar{y}_{i j k}=\mu+\tau_{i}+\delta_{j}+\zeta_{k}+(\tau \delta)_{i j}+$ $(\tau \zeta)_{i k}+(\delta \zeta)_{j k}+(\tau \delta \zeta)_{i j k}+\bar{\varepsilon}_{i j k}$

em que, $\bar{y}_{i j k}$ é o valor genético direto para $\mathrm{P} 205 ; \mu$ é a média geral de todos os genótipos; $\tau_{\mathrm{i}}$ é o efeito aditivo do genótipo $i ; \delta_{\mathrm{j}}$ é o efeito aditivo de ambiente $j ; \zeta_{\mathrm{k}}$ é o efeito aditivo do regime alimentar $k ;(\tau \delta)_{\mathrm{ij}}$ é a interação do genótipo $i$ no ambiente $\mathrm{j} ;(\tau \zeta)_{\mathrm{ik}}$ é a interação GF do genótipo $i$ no regime alimentar $k ;(\delta \zeta)_{\mathrm{jk}}$ é a interação EF do ambiente $j$ e no regime alimentar $k ;(\tau \delta \zeta)_{\mathrm{ijk}}$ é a interação GEF de três modos do genótipo $i$ no ambiente $j$ e no regime alimentar $k$; e $\varepsilon_{\mathrm{ijk}}$ é o erro médio.

O modelo proposto por TUCKER (1966) para a interação do modelo de três modos é:

$(\tau \delta \zeta)_{\mathrm{ijk}}=\mathrm{Z}_{\mathrm{ijk}}=\Sigma_{\mathrm{p}=1}^{\mathrm{P}} \Sigma_{\mathrm{q}=1}^{\mathrm{Q}} \sum_{\mathrm{r}=1}^{\mathrm{R}} g_{p q r} a_{i p} b_{j q} c_{k r}$

em que $a_{i p}, b_{j q}, e c_{k r}$ são os elementos dos componentes principais das matrizes $\mathrm{A}, \mathrm{B}$ e $\mathrm{C}$, associados com cada modo, e $g_{p q r}$ são os elementos dos três modos do arranjo $\mathrm{G}$, que fornece relações entre os componentes principais (primeira, segunda, terceira, etc) dos três modos, fornecendo a proporção da variabilidade representada por cada combinação dos componentes dos três modos.

$P$ é a classificação de $Z_{1: 2} \subset_{3}$, que contém os resíduos da interação tripla, em que as linhas são o primeiro fator (genótipo) e as colunas são a combinação do segundo e terceiro fator (local e regime alimentar), portanto, $Z_{1 ; 2} \subset_{3}$ é de ordem $I \times J K$. Do mesmo modo que $Q$ e $R$ representam a classificação das matrizes $Z_{2 ; 1} \subset{ }_{3} \mathrm{e}$ $Z_{3 ; 2} \subset_{3}$ de ordem $J \times I K$ e $K \times I J$, respectivamente. Como mencionado, o arranjo $\mathrm{G}$ representa 3 modos de ordem $P \times Q \times R$, com elementos indicando o relacionamento entre os componentes de cada modo, i.e., o elemento $g_{p q r}$ mostra o relacionamento entre o componente $p$ ésimo do primeiro modo.

$\mathrm{O}$ valor de $\left(g_{p q r}\right)^{2}$ indica a variabilidade explicada pela combinação dos fatores. O arranjo de três modos em $G$ pode ser considerado uma 
generalização da matriz diagonal dos autovalores obtidos a partir da decomposição em valores singulares de uma matriz de dois modos. Todas as rotinas para a análise dos componentes de três modos foram implementadas e analisadas utilizando o software MATLAB (2007).

Como o estudo da IGA por meio da análise de componentes de três modos nunca tinha sido aplicada a dados de bovinos, utilizaram-se duas outras técnicas comuns como critério de comparação. A primeira envolveu o cálculo das correlações entre os valores genéticos dos touros nos ambientes e a segunda, a análise de agrupamento dos ambientes, tendo os valores genéticos dos touros como variáveis. Utilizou-se a correlação linear de Pearson para analisar a associação entre os valores genéticos dos touros nos diferentes locais e regimes alimentares por meio do software SAS (SAS, 2003).

$\mathrm{Na}$ análise de agrupamento, a contribuição relativa de cada variável para a diversidade entre os ambientes foi obtida pela metodologia proposta por SINGH (1981), utilizando o programa computacional GENES (CRUZ, 2008). Os agrupamentos das seis combinações (R1F1, R2F1, R3F1, R1F2, R2F2, R3F2) foram obtidos pelos métodos de UPGMA (SNEATH \& SOKAL, 1973), utilizando a distância euclidiana média como medida de dissimilaridade. A validação dos agrupamentos foi determinada pelo coeficiente de correlação cofenético (r). Foi utilizado o programa GENES para as análises de dissimilaridade e de correlação cofenética e o programa Statistical 7.0 para a análise de agrupamento.

\section{RESULTADOS E DISCUSSÃO}

Os pesos médios observados para o regime alimentar exclusivo a pasto foram $177,88 \pm 32,32 \mathrm{~kg}$, $173,09 \pm 32,73 \mathrm{~kg}$ e $170,37 \pm 31,47 \mathrm{~kg}$ para as regiões Maranhão, Mata e Agreste e Recôncavo Baiano, respectivamente. $\mathrm{Na}$ mesma ordem, os pesos observados para animais suplementados foram $227,99 \pm 43,97 \mathrm{~kg}, 218,62 \pm 46,10 \mathrm{~kg}$ e $217,61 \pm 41,54 \mathrm{~kg}$, respectivamente. A região de produção do Maranhão, por estar localizada em uma zona de transição entre o clima equatorial úmido amazonense e o semi-úmido nordestino, possui uma pequena vantagem edafoclimática em relação às demais regiões de produção nordestina.

As estimativas de variâncias (Tabela 1) estão dentro do intervalo encontrado na literatura (MALHADO et al., 2008 e 2009). Contudo, fica evidenciada a presença de heterogeneidade de variância entre algumas combinações região e regime alimentar. Os menores valores para os componentes de variância residual estimados para a região 3 (Recôncavo Baiano), independentemente do regime alimentar, indicam que as condições ambientais dentro dessa região são mais homogêneas, facilitando a expressão das diferenças genéticas e, consequentemente, elevando os valores dos coeficientes das herdabilidades.

O procedimento proposto por TIMMERMAN \& KIERS (2000) foi usado neste estudo para selecionar o número ótimo de componentes principais para cada modo (ou seja, valores $\mathrm{P}, \mathrm{Q}$ e R). O melhor modelo de ajuste fornece dois componentes para o modo de genótipos (matriz A), dois componentes para o modo localização (matriz B) e dois componentes para o modo de sistema de alimentação (matriz C) (ou seja, $2 \times 2 \times 2$ ). Esses componentes explicaram $91,94 \%$ da variância total. Os dois componentes do modo genótipo, P1 e P2, explicaram 61,88 e 30,07\% da variância, respectivamente; os dois componentes, Q1 e Q2, no modo local, descreveram 87,05 e 4,90\% da variância, respectivamente; e os dois componentes do sistema de alimentação, R1 e R2, explicaram 60,10 e $31,85 \%$ da variância, respectivamente.

Tabela 1 - Componentes de variâncias e herdabilidades (efeito direto) para as regiões (R1:Maranhão, R2:Mata e Agreste e R3:Recôncavo Baiano) e regimes alimentares (F1:pasto e F2:suplementação) para a característica peso aos 205 dias de idade, em bovinos da raça Nelore.

\begin{tabular}{|c|c|c|c|c|c|c|c|c|c|c|c|c|}
\hline \multirow{2}{*}{ Região } & \multicolumn{6}{|c|}{ - } & \multicolumn{6}{|c|}{ 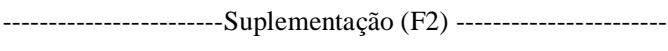 } \\
\hline & $\sigma_{\mathrm{a}}^{2}$ & $\sigma_{\mathrm{m}}^{2}$ & $\sigma_{\mathrm{ep}}^{2}$ & $\sigma_{\mathrm{e}}^{2}$ & $\sigma_{\mathrm{p}}^{2}$ & $h^{2}$ & $\sigma_{\mathrm{a}}^{2}$ & $\sigma_{\mathrm{m}}^{2}$ & $\sigma_{\mathrm{ep}}^{2}$ & $\sigma_{\mathrm{e}}^{2}$ & $\sigma_{\mathrm{p}}^{2}$ & $h^{2}$ \\
\hline $\mathrm{R} 1$ & 161,9 & 54,1 & 45,2 & 270,4 & 531,61 & 0,30 & 116,1 & 40,2 & 50,3 & 810,0 & 1016,6 & 0,11 \\
\hline $\mathrm{R} 2$ & 165,1 & 60,5 & 30,2 & 311,5 & 567,2 & 0,29 & 385,7 & 70,2 & 20,8 & 410,1 & 886,8 & 0,43 \\
\hline R3 & 308,7 & 42,4 & 28,7 & 202,3 & 582,1 & 0,53 & 308,6 & 60,9 & 19,3 & 267,2 & 656,0 & 0,47 \\
\hline
\end{tabular}

$\sigma_{\mathrm{a}}^{2}$ : variância genética aditiva direta; $\sigma_{\mathrm{m}}^{2}$ : variância genética aditiva materna; $\sigma_{\mathrm{ep}}^{2}$ : variância de ambiente permanente materno; $\sigma_{\mathrm{e}}{ }^{2}$ : variância ambiental; $\sigma_{\mathrm{p}}^{2}$ : variância fenotípica $\mathrm{e} \mathrm{h}^{2}$ : herdabilidade direta. 
No biplot, as distâncias entre indivíduos são interpretadas como dissimilaridades entre eles e interpreta-se o comprimento dos vetores que representam as variáveis em termos de variabilidade e os ângulos entre dois vetores em termos de suas correlações (Figura 1). A relação indivíduo-variável é analisada por meio da projeção dos pontos que representam os indivíduos sobre os vetores que representam as variáveis. Tomando-se como exemplo o touro 34 , a sua projeção sobre o vetor que representa o regime com suplementação, indica interação positiva, enquanto, o vetor sobre o regime alimentar a pasto, demonstra interação negativa.

Primeiramente, pode-se notar no biplot que o aspecto mais relevante da interação é que os vetores para cada regime alimentar possuem a mesma direção, indicando que os animais interagem em maior magnitude com o regime alimentar, possuindo comportamento similar em cada regime, independentemente da região de produção. Essa constatação é importante e sinaliza que os bovinos estudados possuem estabilidade nas diferenças edafoclimáticas dos três ambientes, além de a região de produção não interagir com a característica estudada, assim os animais com performances superiores ou inferiores a pasto ou com suplementação terão essa característica nas três regiões de produção. Esse é o principal resultado deste estudo e não corrobora os resultados reportados por LOPES et al. (2008). Esses autores relataram interação genótipo versus ambiente entre os três estados da região Sul. Essa contradição, provavelmente, é consequência da grande diferença entre os sistemas de criação da região Nordeste e da região Sul e dos genótipos dos animais.

Os animais 60,15 e 33 interagem positivamente com o sistema a pasto e negativamente com o regime com suplementação, enquanto os touros 34 e 14 possuem comportamento inverso, interagindo positivamente com o sistema com suplementação e negativamente a pasto. Esses cinco animais citados são indicados apenas para um regime alimentar, visto que, no outro ambiente, seus valores genéticos são negativos.

Todos os touros entre os dois vetores (por exemplo, 40, 57, 17 e 21) possuem interação positiva nos três ambientes e nos dois regimes alimentares. Esses touros interagiram positivamente, com bom desempenho em todos os ambientes e/ou regimes alimentares. Os reprodutores próximos à origem dos eixos (por exemplo, 49, 27, 12, 28, 9, 20 e 30) são ditos estáveis, possuindo comportamento previsível nos diferentes ambientes, isto é, não interagem positivamente ou negativamente com nenhum local de produção ou regime alimentar.

As correlações entre os valores genéticos dos touros nas três regiões com regime a pasto foram significativas $(\mathrm{P}<0,001)$ e acima de 0.9 (Tabela 2). Já as

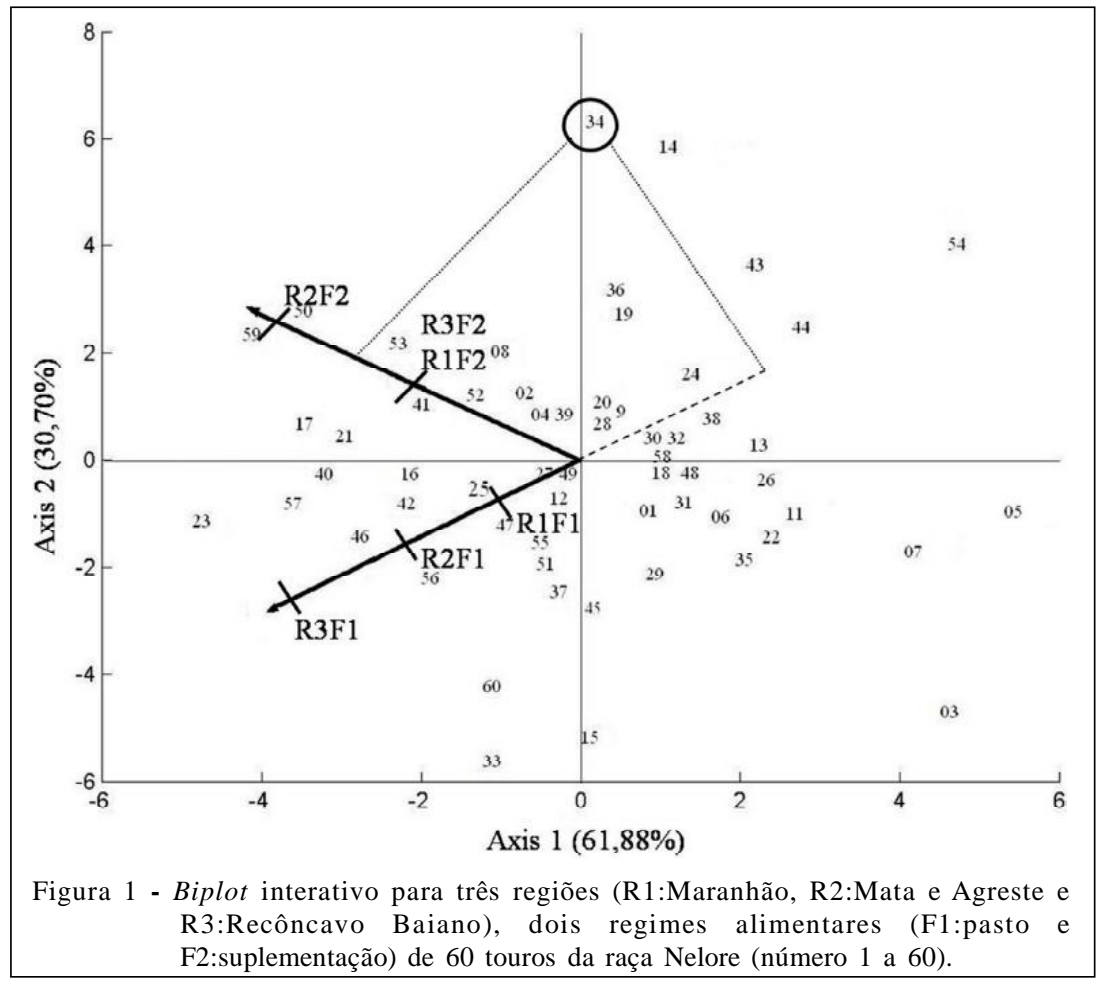

Ciência Rural, v.42, n.12, dez, 2012. 
Tabela 2 - Coeficientes de correlações de Pearson entre os valores genéticos dos 60 touros da raça Nelore para as combinações regiões (R1:Maranhão, R2:Mata e Agreste e R3:Recôncavo Baiano) e regimes alimentares (F1:pasto e F2:suplementação).

\begin{tabular}{lccccc}
\hline Região/Regime Alimentar & R2F1 & R3F1 & R1F2 & R2F2 & R3F2 \\
\hline R1F1 & $0,99^{* * *}$ & $0,92^{* * *}$ & $0,28^{*}$ & $0,27^{*}$ & $0,19^{\mathrm{ns}}$ \\
R2F1 & - & $0,95^{* * *}$ & $0,29^{*}$ & $0,28^{*}$ & $0,22^{\mathrm{ns}}$ \\
R3F1 & - & - & $0,31^{* *}$ & $031^{* *}$ & $0,30^{*}$ \\
R1F2 & - & - & - & $0.97^{* * *}$ & $0,70^{* * *}$ \\
R2F2 & - & - & - & - & $0,64^{* * *}$ \\
\hline
\end{tabular}

${ }^{1}$ ns: não significativo, *: $\mathrm{P}<0,05, * *: \mathrm{P}<0,01 \mathrm{e} * * *: \mathrm{P}<0,001$.

correlações entre os regimes alimentares, independente da região, foram todas inferiores a 0,30. Valores significativos $(\mathrm{P}<0,001)$ e iguais a 0,97 (R1F2 e R2F2), 0,70 (R1F2 e R3F2) e 0,64 (R2F2 e R3F2) foram encontrados para as três regiões no regime com suplementação. A interação genótipo versus ambiente só tem importância para a agropecuária se a correlação genética entre a mesma característica em diferentes ambientes for inferior a 0.8 (ROBERTSON, 1959).

De acordo com a literatura tradicional, correlação genética baixa significa que os genes relacionados ao crescimento em um regime alimentar não são os mesmos genes responsáveis pela expressão desta característica em outro regime alimentar. Contudo, devemos salientar que a organização da cromatina exerce função chave na determinação de padrões de expressão gênica e pesquisas futuras com epigenética poderão auxiliar o entendimento genômico da interação genótipo versus ambiente.

O dendrograma resultante da análise de agrupamento das seis combinações (região e regime alimentar) corrobora os resultados por três modos de componentes principais (Figura 2). O ponto de corte no dendrograma, utilizando-se a média da matriz de dissimilaridade, indica a formação de dois grupos, o primeiro formado pelos animais criados a pasto, o segundo com animais com suplementação. O coeficiente de correlação cofenético entre a matriz de dissimilaridade e a matriz de agrupamento foi igual a 0,84 , evidenciando a consistência do agrupamento. Os touros que mais contribuíram para a divergência das combinações região-regime foram os animais 34 $(7,54 \%), 33(7,53 \%), 3(7,53 \%), 15(6,41 \%), 14(5,67 \%)$ e $60(4,26 \%)$. É importante destacar que todos esses animais possuem forte interação com o regime alimentar e, dessa forma, seu uso deve ser direcionado de acordo com o regime de criação de seus filhos. Destaca-se, com esses resultados, que o regime alimentar é o efeito ambiental mais importante para a interação genótipoambiente na raça Nelore no Nordeste. Assim, as condições edafoclimáticas de cada região, apesar de influenciarem na produção de forragens são menos importantes que a suplementação ou não dos animais. Já os touros com menores contribuições para a divergência são aqueles próximos da origem do eixo.

Para FALCONER \& MACKAY (1996), uma característica mensurada em dois ambientes diferentes deve ser considerada não como uma, mas como duas características, isso porque os mecanismos fisiológicos nos dois ambientes são, em alguma extensão, diferentes e, consequentemente, os genes requeridos para um elevado desempenho também são, de certa forma, diferentes para os dois ambientes. Assumindo essa ideia como verdadeira, a seleção de animais em ambientes diferentes daqueles nos quais suas progênies irão produzir não seria uma escolha adequada. Isso é particularmente importante na região Nordeste, onde a maior parte da carne produzida é proveniente de sistema de produção a pasto, enquanto parte dos rebanhos de elite são mantidos em condições ambientais muito diferentes daquelas nas quais estão submetidos os rebanhos comerciais.

Nesse sentido, CORRÊA et al. (2007) frisaram que a interação genótipo-ambiente pode prejudicar o progresso genético das populações de bovinos de corte pelo uso inadequado de reprodutores. Segundo os autores, determinados genótipos podem vir a apresentar baixo desempenho, se utilizado em ambiente muito diferente ao que foi selecionado, devendo-se priorizar a utilização de material genético de animais que sejam verdadeiramente "superiores" nas condições específicas de criação.

\section{CONCLUSÃO}

Constatou-se interação genótipo $\mathrm{x}$ regime alimentar por meio da técnica de componentes principais de três modos, resultado que foi corroborado por outras duas outras técnicas usuais (correlação genética e análise de agrupamento). A utilização dos touros deve ser direcionada de acordo com o regime alimentar de criação de seus filhos. 


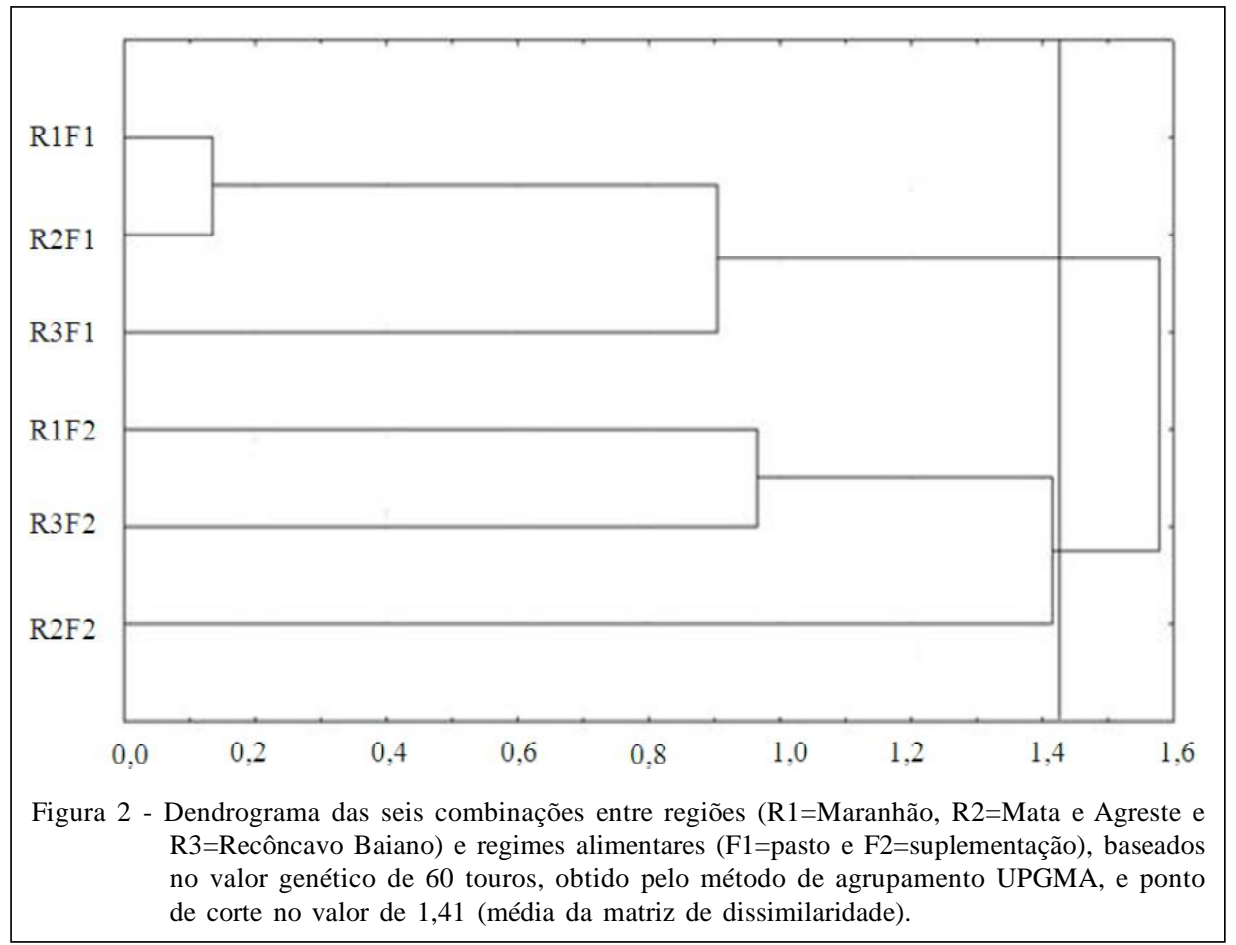

\section{REFERÊNCIAS}

ARAÚJO, L.B. et al. Gráficos biplot e joint plot para o estudo da interação tripla. Ciência Rural, v.40, p.833-839, 2010. Disponível em: 〈http://www.scielo.br/pdf/cr/v40n4/a537cr2054.pdf>. Acesso em: 10 jul. 2012.

ARAÚJO, L.B. et al. Multiattribute response of maize genotypes tested in different coastal regions of Brazil. International Journal of Agronomy, on-line, n.p, 2011. Disponível em: <http://www.hindawi.com/journals/ija/2011/215843/>. Acesso em: 10 jul. 2012. doi: 10.1155/2011/215843.

ARRUDA, Z.J. de; SUGAI, Y. Regionalização da pecuária bovina no Brasil. Campo Grande: Embrapa-CNPGC; Brasília: Embrapa-SPI, 1994. 144p. (Embrapa-CNPGC. Documentos, 58).

BOLDMAN, K.G. et al. A manual for use of MTDFREML; a set of programs to obtain estimates of variances and covariances [DRAFT]. Lincoln: Department of Agriculture, Agricultural Research Service, 1995. 120p. Disponível em: <ftp://aipl.arsusda.gov/pub/outgoing/mtdfreml/mtdfrman.pdf>. Acesso em: 25 fev. 2012

CORRÊA, M.B.B. et al. Efeito da interação genótipo-ambiente na avaliação genética de bovinos de corte. Revista Brasileira Agrociência, v.13, p.153-159, 2007. Disponível em: <http:/ /www.ufpel.edu.br/faem/agrociencia/v13n2/artigo03.pdf>. Acesso em: 25 fev. 2012.

CRUZ, C.D. Programa genes (versão Windows): aplicativo computacional em genética e estatística. Viçosa: UFV, 2008. Disponível em <http://www.ufv.br/dbg/genes/Genes_Br.htm>. Acesso em: 25 fev. 2012.
ELER, J.P. et al. Influência da interação touro $\mathrm{x}$ rebanho na estimação da correlação entre os efeitos genéticos direto e materno em bovinos da raça Nelore. Revista Brasileira de Zootecnia, v.29, n.6, p.1642-1648, 2000. Disponível em: <http://www.scielo.br/scielo.php?pid=S 1516 $35982000000600007 \&$ script $=$ sci_arttext $>$. Acesso em: $25 \mathrm{de}$ fev. 2012. doi: 10.1590/S1516-35982000000600007.

FALCONER, D.S.; MACKAY, T.F.C. Introduction to quantitative genetics. 4.ed. Harlow: Longman, 1996. 464p.

FRIDRICH, A.B. et al. Interação genótipo $\mathrm{x}$ ambiente e estimativas de parâmetros genéticos dos pesos aos 205 e 365 dias de idade de bovinos Nelore. Arquivo Brasileiro de Medicina Veterinária e Zootecnia, v.60, p.917-925, 2008. Disponível em: <http://www.scielo.br/scielo.php?pid=S0102$09352008000400022 \&$ script $=$ sci_arttext $>$. Acesso em: $25 \mathrm{fev}$. 2012. doi: 10.1590/S0102-09352008000400022.

LOPES, J.S. et al. Efeito da interação genótipo ambiente sobre o peso ao nascimento, aos 205 e aos 550 dias de idade de bovinos da raça Nelore na Região Sul do Brasil. Revista Brasileira Zootecnia, v.37, p.54-60, 2008. Disponível em <http:// www.scielo.br/scielo.php?script $=$ sci_arttext\&pid $=$ S 1516 $35982008000100007 \& \operatorname{lng}=\mathrm{en} \& \mathrm{nrm}=\mathrm{iso}>$. Acesso em: $25 \mathrm{fev}$. 2012. doi: 10.1590/S1516-35982008000100007.

MALHADO, C.H.M. et al. Progresso genético e estrutura populacional do rebanho Nelore no Estado da Bahia. Pesquisa agropecuária brasileira, v.43, p.1163-1169, 2008. Disponível em: <http://www.scielo.br/scielo.php?script=sci_arttext\&pid=S0100204X2008000900010\&lng=en\&nrm=iso>. Acesso em: 25 fev. 2012. doi: 10.1590/S0100-204X2008000900010. 
MALHADO, C.H.M. et al. Histórico genético e populacional do rebanho Nelore puro de origem no sertão nordestino. Pesquisa Agropecuária Brasileira, v.44, n.7, p.713-718, 2009. Disponível em: <http://www.scielo.br/scielo.php?script=sci_arttext\&pid=S0100204X2009000700010\&lng=en\&nrm=iso>. Acesso em: $25 \mathrm{fev}$. 2012. doi: 10.1590/S0100-204X2009000700010.

MATLAB. The language technical computing R2007. São Paulo, 2007. 152p.

ROBERTSON, A. The sampling variance of the genetic correlation coefficient. Biometrics, v.15, n.3, p.469-485, 1959. Disponível em: 〈http://www.jstor.org/pss/2527750〉. Acesso em: 25 fev. 2012.

SAS Institute. SAS: user guide: versão 9.1. Cary, 2003. 176p.

SINGH, D. The relative importance of characters affecting genetic divergence. Indian Journal of Genetic Plant Breeding, v.41, n.2, p.237-245, 1981. Disponível em: <http:/ / w w w . i n d i a $\mathrm{n}$ j o u r n a l s . c o m / ijor. aspx ?target $=$ ijor:ijgpb $\&$ volume $=41 \&$ issue $=2 \&$ article $=010$ > . Acesso em: 25 fev. 2012.

SNEATH, P.H.; SOKAL, R.R. Numerical taxonomy: the principles and practice of numerical classification. San Francisco: W.H. Freeman, 1973. 573p.
SOUZA, J.C. et al. Estimates of genetic parameters and evaluation of genotype $\mathrm{x}$ environment interaction for weaning weight in Nellore cattle. Archivos Latinoamericanos de Produción Animal, v.11, n.2, p.94-100, 2003. Disponível em: 〈http://ojs.alpa.org.ve/index.php/ojs_files/article/view/39>. Acesso em: 25 fev. 2012.

TORAL, F.L.B. et al. Interação genótipo $\mathrm{x}$ ambiente em características de crescimento de bovinos da raça Nelore no Mato Grosso do Sul. Revista Brasileira Zootecnia, v.33, n.6, p.1445-1455, 2004. Disponível em: <http://www.scielo.br/ scielo.php ? s cript=sci_arttext \& pid=S 1516 $35982004000600011 \& \operatorname{lng}=$ en\&nrm=iso>. Acesso em: $27 \mathrm{fev}$. 2012. doi: 10.1590/S1516-35982004000600011.

TIMMERMAN, M.E; KIERS, H.A.L. Three-mode principal components analysis. Choosing the numbers of components and sensitivity to local optima. British Journal of Mathematical and Statistical Psychology, v.53, p.1-16, 2000. Disponível em: <http://www.gmw.rug.nl/ metimmer/ timmerman2000.pdf>. Acesso em: 26 fev. 2012.

TUCKER, L.R. Some mathematical notes on three-mode factor analysis. Psychometrika, v.31, p.279-311, 1966. Disponível em: <http://www.springerlink.com/content/87x451g73474n136/>. Acesso em: 25 fev. 2012. doi: 10.1007/BF02289464. 